logists favour the use of fixatives containing mercuric chloride. These have several advantages, but the waste is usually disposed of down the sink. The biological consequences of mercury pollution are well recognized, and as industry curtails its contribution the role of pathology laboratories will become more significant, for a busy department may discharge up to $50 \mathrm{~kg}$ of mercury a year. In a recent article ${ }^{1}$ several safe alternatives are outlined, such as the use of zinc chloride or formalin instead of mercuric chloride and the recovery of the mercury as is widely practised by radiologists in the case of silver.-I am, etc.,

St. Thomas's Hospital Medical School,

B. CorrIN 1 Porter, D. D., Archives of Pathology, 1972, 94,
279.

SIR,-Your leading article (30 December, p. 746) is timely. The Deposit of Poisonous Wastes Act 1972 was drafted in haste and with inadequate consultation. This explains, perhaps, the failure of the Act to recognize and utilize the longstanding and useful partnership of the medical officer of health and the public health inspectorate in the boroughs of Greater London, and instead vests all the enforcement powers with the Greater London Council. The G.L.C. is of course a body with tremendous expertise and we are glad to be able to utilize it. However, since it is the local health authority which is responsible for the public health and is also likely to receive the first intimation of illegal dumping, we feel that amending legislation should be enacted to give concurrent powers to the London boroughs. It is also important clearly to establish the role of the medical officer of health's successor in "community medicine" in these matters.-We are, etc.,

J. K. ANAND

Deputy Medical Officer of Health

E. W. WARD

Chief Public Health Inspector London Borough of Redbridge Health Department, Ilford, Essex

\section{Rh "Null" is Not Always Null}

SIR,-Recently members of two unrelated families with $R h_{\text {null disease living in West }}$ Virginia were brought to our attention. The first family was referred to us for investigation when an Army private, presenting with a marked haemolytic anaemia and splenomegaly, was found to be $\mathbf{R h}_{\text {null. Of }}$ seven siblings tested, one sister, aged 25 years, was found also to be $\mathbf{R} \mathbf{h}_{\text {null }}$. Further investigations showed evidence of a compensated haemolytic anaemia with a reticulocytosis, mild spherocytosis, and abnormal autohaemolysis and osmotic fragility of the red cells. The cells were $\mathrm{M}+\mathrm{N}+, \mathrm{S}-\mathrm{s}+$, LW-, $U$ weakly positive, and $G$ negative. The parents, first cousins, were of the genotype R1R1 and $R 1 \mathbf{r}$ and were $\mathrm{LW}+, \mathrm{U}+$. There was no attenuation of the $R h$ antigens of the parents or of the six normal siblings. These findings are similar to those in other parients with the rare regulator type of $\mathrm{Rh}_{\text {null. }}{ }^{12}$

Drs. R. Sanger and P. Tippett kindly examined a sample of blood from the sister; they confirmed the typing results and agreed with us that, although the cells typed as
$\mathrm{Rh}_{\text {null, }}$ there was evidence of traces of $\mathrm{D}$ antigen on the subject's cells. Absorption tests with six different anti-D sera and the subject's red cells showed that they were capable of absorbing anti-D activity. Heat eluates from these $R_{h_{\text {null }}}$ cells reacted with D-positive cells in the antiglobulin test using broad-spectrum Coombs reagent and specific anti-IgG, but not with specific anti-IgA or anti-IgM sera. A small reduction in the anti-D titre was observed in all the absorbed sera. A reduction in the titre of the specific anti-IgG serum was also found. Absorption studies with one example of anti-C and anti-c serum did not result in the removal of antibody activity.

The second person studied was a sister, aged 46 , of the patient reported by Dr. P. Sturgeon. ${ }^{3}$ Typing showed her to be $\mathbf{R h}_{\text {null, }}$ LW-, G-, and $\mathrm{U}+$. Unlike the first patient's sister, absorption and elution studies of her red cells with anti-D-containing sera did not show that the antibody had attached to her cells.

This report supports the concept that

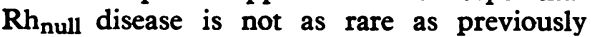
thought and that in some, but not all, patients the presence of the $D$ antigen may be demonstrated by conventional means.We are, etc.,

M. M. Stevenson V. ANIDO

A. M. TANNER West Virginia University Medical Centre, J. SWOYER Morgantown W. Virginia

1 Levine, P., Celano, M. J., Falkowski, F., Chambers, J. W., Hunter, O. B., and English, C. T., Transfusion, 1965, 5, 492

Schmidt, P. J., Lostumbo, M. M., English, C. T., and Hunter, O. B., Transfusion, 1967, 7, 33.
Sturgeon, P., Blood, 1970, 36, 310.

\section{Effects of Tranquillizers and Hypnotics} on Driving

SIR,-We have been studying the persistent effects of hypnotics and tranquillizers, and are therefore interested in the investigation of Dr. T. A. Betts and others (9 December, p. 580) into the effects of different tranquillizing drugs on normal subjects' lowspeed driving performance. They have shown that the latter can be impaired by five doses of drug taken over the preceding 36 hours and suggest that this may be important in relation to drug administration in patients. However, they have not investigated the sort of patient for whom these drugs might be prescribed.

Our group at the London Hospital studied normal subjects' cognitive and motor performance, using digit symbol substitution and card sorting, and found that this may be impaired by a single dose of amylobarbitone or nitrazepam given the previous night. ${ }^{1}$ Because we doubted whether this observation was relevant to the usual therapeutic situation, we undertook a similar investigation on anxious patients, who received drug or placebo over seven days. These patients were tested 18 hours after the last dose and showed no impairment on the tasks. Electroencephalograms taken on the same occasion showed higher scores for drowsiness after drug than after placebo, but the scores were much lower than those previously obtained in normal subjects. (The results of this investigation are to be published in detail later.)

These results cannot be extrapolated direct to normal driving performance, but hey indicate that tranquillizers and hypnotics may effect the performance of normal subjects and anxious patients in different ways. Dr. Betts and his colleagues recommend that patients who are to take tranquillizers should be warned about possible adverse effects on their driving. However, we feel that neither their investigations nor ours are directly applicable to what in practice is the effect on driving of taking or indeed withdrawing tranquillizers in patients. Our researches strongly suggest that further studies with patients will be required before this question can be answered.-We are, etc.,

Imperial Cancer Research Fund,

N. J. LEGG

London Hospital Medical College,

ANN MaLPas

London E.1

The London Hospital

D. F. ScOTT

The London $\mathrm{E} .1$

Malpas, A., Rowan, A. J., Joyce, O. R. B., and
Scott, D. F., British Medical foumal, 1970, 2, 762 .

\section{Two Radiologists-Holland and Britain}

SIR,-I opened my B.M.f. of 27 January and turned with eager anticipation to page 225 to read of "Two Radiologists-Holland and Britain," but was disappointed when doubts arose as to whether the comparison was between like and like. Many radiologists in Britain would not recognize the life-style and work-style of Dr. Rushton-Wilson.

"Along with his three colleagues he does at least half a day's service work a week-routine barium meals, angiograms, and so on-and he is on duty one week in four. Every day he attends clinical sessions, with the physicians, surgeons, radiotherapists, or specialist groups such as the haematological unit, and usually he goes to the necropsy demonstrations as well."

One session of service work each week is a poor return to give to the populace which pays him his salary. Clinical sessions and visits to the necropsy room are valuable contributions to one's vicarious experience, in which one can discuss other people's work, but are no substitute for personal experience, which at one session a week will be achieved but slowly.

Many of us are doing not less than one half-day of service work each day, five days a week - that, is five half-days each week. A round half-dozen of us within 30 miles of this city are doing just this service load each, each week, and possibly more. By Dr. Rushton-Wilson's standards we should be replaced by 30 whole-time consultants, each doing one half-day a week of service load. As some $90 \%$ of the hospital service load of the country is being done in non-teaching hospitals, where radiologists generally work under conditions similar to my own, the consequence would be to wreck the Health Service and introduce a demand for radiologists which would scarcely be met even if all our medical students destined for the hospital services were diverted into radiology.

Were we to reduce our service load to one-fifth of what it is now we would certainly need a day of research each week, if only as "occupational therapv"l_to keep our brains warm and check that they are still there.

Let us see more "European Counterparts," but may we not see similar articles on con- 
ditions at home in Britain under the title, forthcoming. Once working conditions have let us say, of "Them and Us"?-I am, etc.,

ANTHONY A. VICKERS

Worcester

1 Platt, Lord, British Medical fournal, 1967, 4, 439.

SiR,-Your article (27 January, p. 225) was mildy interesting, but the life and work and problems of the British radiologist concerned are so far removed from those of the generality of the specialty that they are of little general concern.

The great majority of British radiologists, according to Dr. Rushton-Wilson, are condemned to a troglodytic existence in a basement surrounded by an unending pile of films for reporting, seeing neither colleagues nor patients, and having no idea whether their reports are true or false or even relevant. Dr. Rushton-Wilson is concerned (as are we all) by the shortage of British radiologists, but to suggest that this is all they will have to look forward to is hardly likely to encourage recruitment.

All this would not matter, but your journal is supposed to carry some authority, and a true picture of the life and work of a more generally representative radiologist might be of considerably more interest and value. We do not all live in basements, and even outside teaching hospitals, many of us have good contact with clinical colleagues and meet regularly to discuss films and problems, quite apart from informal contact over the lunch table. Some of us even find time for useful research; though in the very nature of the job, we do spend a lot of time reporting routine films and we do rnore than one half-day a week of service work. Most of Dr. Rushton-Wilson's registrars will end up in this sort of a life, so perhaps he should find out more accurately what their life and work will be so that he can teach them what they should be learning. -I am, etc.,

York

J. K. Johnson

\section{Shortage of Radiologists}

SIR,-Dr. J. P. Grier suggests (3 February, p. 292) that the shortage of radiologists is the limiting factor in radiological services in his area. Personally, $I$ find that the lack of purpose-built facilities, the large proportion of obsolete and inconvenient equipment, and the shortage of ancillary staff are the limiting factors in the amount of work I am able to do.

Given a well-equipped, purpose-built department, an increase in throughput of 10$15 \%$ would not be impossible. The problem is practically universal in the older peripheral hospitals and is simply an expression of the shoe-string improvization seen outside teaching hospitals. Radiology is an expensive business which is always expanding and one which is probably unique in its dependence on its equipment for the quality of its results.

If we are to have any hope of keeping pace with the expanding work load, let alone the demand for open access facilities from general practitioners, priority must be given to modernization of $x$-ray departments -especially those in future district general hospitals-and adequate funds must be board and a new machinery to need to be Oxford
London E.11

C. P. COOPER improved, solution of any staffing problems will not be far behind.-I am, etc.,

\section{Dangerous Patients}

SIR,-May I take up three points in your leading article "Dangerous Patients" (3 February, p. 247)?

(1) The advantage of the indefinite restriction order over those for finite periods lies not so much in the fact of prognostication to which you allude but in the fact that the indefinite restriction order allows the patient to live outside hospital under conditional discharge for as long as is thought necessary clinically by the responsible medical officer in conjunction, of course, with the Home Secretary. The resultant increased flexibility often permits of much earlier discharge of the patient, particularly when it is realized that under an ordinary section 60 order, which is what a section 65 order for a finite period becomes after the period in question has expired, the 28 days of successful absconding means automatic and complete freedom. On the other hand, recurrence of disorder leading to the failure to fulfil the conditions of a conditional discharge can, for an indefinite length of time, mean the restitution of the section 65 order.

(2) I cannot understand how you can say in successive paragraphs that you object to N.H.S. hospitals playing a role in the treatment (and indeed in the rehabilitation) of previously dangerous patients under restrictions coming from the special hospitals; and that you find the existing arrangements sufficient to protect the public, since the existing arrangements are the very ones which involve the N.H.S. hospitals in accepting patients from the special hospitals. I personally can see no possible objection to suitable patients passing through the N.H.S. hospitals rather than directly to hostels (even if such hostels existed or were likelv to exist in the foreseeable future). Surely proper flexibility requires the cooperative interplay of the special hospitals, medium security hospitals of the sort envisaged by the Oxford Regional Hospital Board, ordinary and open N.H.S. hospitals, and hostels.

(3) I am afraid I do not understand the point you make about the independent psychiatrist at the bottom of paragraph five of your article. The psychiatrist who examines a patient on behalf of the Mental Health Review Tribunal is not independent of that tribunal, though he is independent of the hospital: the forensic psychiatrist on the proposed advisory board would be equally independent of the hospital and qually un-independent of the advisory board of which he is a member. Or have I misunderstood? Surely the moot point here is whether the new advisory boards would differ significantly enough from the existing mental health tribunals for a new type of set up, particularly when section 60 (6) of the present Act seems to supply the Home Secretary already with all the power that he needs. - I am, etc.,

SEYMOUR SPENCER
Toxicity of Benorylate

SIR,-I read with interest Dr. R. E. HopeSimpson's experience with benorylate (3 February, p. 296).

I have recently finished a double-blind study of benorylate and ibuprofen in 24 patients with classic rheumatoid disease. The study was for a period of eight weeks, with three weeks on each drug and a washout period in between. A point of particular interest was the symptom of tinnitus, which was complained of by four patients on benorylate in this series, sometimes associated with deafness. However, tinnitus with benorylate should not be regarded as a side effect but merely an indication that adequate salicylate levels have been achieved. An adjustment in the dose should relieve this symptom.

In most cases both drugs, apart from producing symptomatic relief, were found to reduce swelling and improve grip strength and functional capacity. There was also a reduction in erythrocyte sedimentation rate even in this short period. Out of 16 patients who stated a preference, 13 preferred benorylate. This study would therefore seem to indicate that benorylate is extremely useful as an antirheumatic agent.-I am, etc.,

Queen Elizabeth Hospital

K. HINGORANI

Gateshead

\section{Subtypes of Hepatitis B Antigen}

SIR,-In their most interesting report on the distribution of hepatitis $B$ antigen subtypes in Swedish blood donors and in patients with post-transfusion hepatitis, Dr. Sten Iwarson and others (13 January, p. 84) discuss the possibility of differences in infectivity and in pathogenicity between the two subtypes ad and ay. They conclude, however, that the different distribution of the subtypes in their groups "might reflect epidemiological circumstances rather than biological differences in the two viral strains."

Studies of the subtype distribution in the same categories of patients in Copenhagen support the epidemiological hypothesis. 1 Subtype ad was found in $89(95 \%)$ of 94 apparently healthy carrier of hepatitis B antigen and in $11(92 \%)$ of 12 patients with post-transfusion hepatitis. Subtype ad also occurred in all of 17 patients with chronic hepatitis or cirrhosis of the liver and in 14 out of 15 patients with acute hepatitis without any known parenteral exposure or drug addiction. The only group of Danes, except for Greenlanders, in whom subtype $a y$ is prevalent is drug addicts. Of these, 37 out of 42 yielded subtype ay, regardless of whether they were apparently healthy carriers or had acute hepatitis.

These findings agree with the opinion that the hepatitis $\mathbf{B}$ antigen subtypes are epidemiological markers of different strains of hepatitis B virus occurring in different population groups. However, these two strains of virus apparently show no difference in their ability to induce a healthy carrier state, acute hepatitis, or chronic liver disease.-I am, etc.,

Bispebjerg Hospital, Copenhagen, Denmark

Peter SkinhøJ 